\title{
The Aesthetic Education Thoughts of "The book of Rites" on Contemporary University Education
}

\author{
Zhejia Tang \\ College of Humanities and Social Sciences, China Jiliang University, Hangzhou 310000,China
}

1540526128@qq.com

Keywords: Aesthetic thoughts; Education; "The Book of Rites"; JunZi; LiYue

\begin{abstract}
The Book of Rites" contains abundant aesthetic thoughts, the development of ancient literati thought in the long history of our country, and the profound influence on Chinese national culture and spirit. Aesthetic education is a education which can purify the emotion and spirit of people, so that people's spirit can be sublimated and promoted. College students' aesthetic education is a very important part of education. It is of great significance to explore the aesthetic education of "the Book of Rites", discard the dross, extract its essence, and take a critical reference. It is of great significance to apply the aesthetic education of "the Book of Rites" to the aesthetic education of college students. This article based on the relevant theories and practical methods, the writer studies the topic by means of the combining perspectives of literature and studying pedagogy. Through the Aesthetic personality, the principle of aesthetic education, the ways of aesthetic education, this paper aims at trying to learn from "the Book of Rites" Education Thoughts refining its contemporary value.
\end{abstract}

\section{The Beauty of Faithful "JunZi" Personality}

The aesthetic cultural patterns of different ethnic groups are always determined by the life styles of different ethnic groups and reflect the style of life of their own. The spirit of aesthetic culture of a nation must ultimately be embodied in the style of life of the nation, and it must be used to reshape the lifestyle of the nation. . China has always been known as the "state of rituals and music". The ritual tradition has laid a foundation for the Chinese people's aesthetic cultural model and life style. It has accumulated as a specific cultural psychological structure and is rooted in the unconsciousness of the national spirit and has affected generations of Chinese. The aesthetic style of life of ancient Chinese people can be summed up as "LiYue life". The"LiYue life" is not only the existence method, norm of behavior, source of value, but also the world of life in ancient Chinese. The book "Book of Rites", which is compiled by Confucius and his disciples in the early Western Han Dynasty, and the pre-Qin confession of Confucianism, is not only the theoretical basis of the country's political life, but also the source of value for people's daily life. The Book of Rites is the result of a meaningful presentation of the "LiYue life".

China has always attached importance to education. Almost all philosophers who have made achievements are educators. They are all keen on various forms of lecturing and education activities. Through their rich educational thoughts and practical activities, we can see that many epochs about education have transcended the times. If we use the "what kind of people should education cultivate and how to cultivate people"to sort out our country's rich educational ideas and practices, then there is a word that can not be bypassed - "JunZi". It can be said that the "JunZi" is the most representative and general expression of China's traditional education goals. The requirement of aesthetic education is to cultivate moral integrity and noble moral character. Confucius's ideal personality is based on loyalty and filial piety, but it also includes masculinity and ethical conduct of people with lofty ideals. As a book on Confucianism, "the Book of Rites" makes a comprehensive summary of the ideal personality in Confucianism. The main content of this aspect can be seen in chapters such as "Biao Ji", "Fang Ji" and "Ru Xing".

In "Ru Xing", we summed up the Confucian's ideal personality in 13 aspects, namely, self-reliance, preparedness, closeness, uniqueness, resoluteness, official career, worrying about the 
country and people, choosing talents, and making friends. It describes how Confucians should behave. The "beauty of loyalty and faith" refers to the principle of persevering in self-improvement, an upright and righteous manner, and an individualism that does not follow the tide. The "beauty of loyalty and faith" is the aesthetic personality that Confucian adheres to, and it is the outstanding side of the Confucian moral tradition. The "beauty of loyalty and faith" has had a positive influence on the traditional Chinese culture of Confucianism.

"The Book of Rites Yuzao" says: "The ancient JunZi must be equipped with jade ... ... no reason for JunZi to live without jade". And in that time normal people are not worthy to equip with jade. Therefore, Mr. Wang Li pointed out: Initially the gentleman is the general name of the nobility of the aristocracy. Most of them are those who have high status in the whole society ."Li", "Yue", "She", "Yu", "Shu", "Shu" are called the six courses and are an important part of the noble education system during the Western Zhou period. Morality classes and the rituals taught by Chinese culture specifically include the "five rites" covering all aspects of politics, ethics, military affairs, society and other legal and moral norms, and are the basis for establishing the country in the Western Zhou Dynasty. So JunZi's action will be in line with the norms, demonstrating the dignity of the nobles, and then they will be able to serve as officials and govern the people.

\section{The Principle of "Gentle and Generous" Aesthetic Education}

"The Book of Rites Yue Ji" says: "Great Yue is in harmony with heaven and earth. The great Li is in the same pace as heaven and earth.... Li, the harmony between heaven and the earth. Yue, the order of heaven and earth." Visible, Confucianism represented by Confucius In terms of schools of thought, the greatest features and functions of "Li" and "Yue" are embodied in "harmony".

"Gentle and honest"is a kind of Chinese-Swiss cultural personality formed by the Confucian's poetic teaching in" the Book of Rites JingJie". In the twenty-sixth chapter, Confucius talks about how a nation is enlightened. If people in this country have soft words and strong temperament, they are taught by "Shi". If they are broad-minded and kind-hearted, they are The enlightenment of "Yue", if they are humbly and thrifty, solemn and respectful, it belongs to the education of "Yue", and if they are meticulously thrifty, courteous and respectful, it belongs to the education of "Li". And "Shi" teaching, "Yue" teaching and "Li" teaching are aesthetic categories. The role of the solution in modern times is to describe the role of education in cultivating good people's qualities. The "Poetry" teaching institute has cultivated a gentle and honest experience. The aesthetic cultural personality of Confucianism is most respected in Confucianism, because it achieves the highest level of human nature.

Ancient Chinese poetry has the tradition that it contains the author's especial emotion and their ambition. Therefore, how to express the author's thoughts and feelings through poetry and convey personal political opinions to the ruler is an important content. The "gentle and honest" aesthetic personality requires the author to describe his opinions to the ruler,using vague and euphemistic words. Admonishment must be based on the premise of not ruining the dignity of the ruler. This requires the author to cultivate a temperament that is "gentle and honest". Otherwise, the sincere advice is not only useless, but also may cause a disaster.

The beauty of Confucianism not only requires harmony of emotion and reason, but from the point of view of music and art, it also requires that the poetic music works must maintain the tone and rhythm and melody simply and harmoniously. This shows that only those musical works that are broad and concise, open-minded and simple and clear-cut rhythm can have a good educational effect on people. "YueJi" further put forward the idea of "Great Yue will be Easy, and Great Li Must Be Simple" on the basis of "JingJie". It is believed that the best music is the "Ya Yue"which has a gentle and simple rhythm.

\section{The Aesthetic Education Way Based on "LiYue"}

The ancient way of aesthetic education is the institutionalization of rites, embodying the restraint of moral rationality on lust, and embodying the civilized course of traditional Chinese moral 
development. As early as the end of the Primitive society, with the gradual establishment of the hierarchy, the concept of respect for the nobles and nobles was increasingly strengthened. The ceremonies appointed by the rulers in a hierarchical society are also given the functions of maintaining and regulating the relation between monarchs and offices, fathers and sons, the old and the young, and men and women. As " the Book of Rites QuLi" says: "the demeanour of the son of heaven should be characterised by majesty;of the princess, by gravity;of the great officers, by a regulated composure; of offices, by an easy alertness; and of the common people,by simplicity and humility."

The so-called "Li" is the institutionalization of the various norms that the ancient Chinese would have accumulated in their daily lives, and with the help of the system, they will further confirm, strengthen, and maintain the hierarchical system of rules, norms of behavior, and ideas that are compatible with them. The purpose of "Li" is to make specific and detailed provisions on people's clothing accessories and many ceremonies that make it easy for everyone to do so that everyone cultivates their awareness of social roles.That is, in a complex social relationship, they clearly identify where they are and know their Status and identity. In the process of accepting "Li" restraints and practicing the requirements of "Li", people are gradually adapting to the subtle influences, and finally cultivated into the custom of establishing etiquette, then they recognize and accept the requirements of " $\mathrm{Li}$ " in the depth of concepts. When people's moral state rises to a certain height, human behavior will be transformed from external constraints into internal consciousness, from heteronomy to self-discipline. Under the rules of "Li," every member of society has defined his position in a strict hierarchical sequence, serving as a specific social role, with respect and understanding of each other. People are all in their position, perform their duties, take care of each other's duties, and give each other their own benefit. "Yue" is not only the external embodiment of the human inner nature, but also the heart and sentiment of people. Therefore, the ancients believed that the music of the world was harmonious and stable; the music of troubled times, the gas of resentment, and the music of the country of extinction were full of sorrow and sadness. If the rhythm of the music is disturbed, there will surely be phenomena of arrogance, bureaucracy, public grievances, lack of money, and so on. Then, the country's death will be quickened. Only a ruler who has both"Li"and "Yue" can be called a virtue.

"Li"and "Yue" are complementary. If "Li" is from the external, objective and compulsory aspects to govern the rank of the subjects, then "Yue" is to obey the patriarchal and national hierarchy from the inner, subjective, and natural aspects. Because both have the function of distinguishing, standardizing, confirming, and maintaining the hierarchy of social relations, the rulers of all ages have advocated and promoted their favor and their willingness. "Li" is used to distinguish people of different ranks, but an overly strict grade will cause people within the society to produce centrifugal force, so "Li" has taken on the task of reconciling the feelings between people of different levels and identities.

\section{The Contemporary Value of the Aesthetic Education Thought in "The Book of Rites"}

The aesthetic education thoughts in "The Book of Rites" are in line with our country's socialist core values. Although the ancient ceremony embodies the arrangement of "noble and humble", it also represents the civilized culture and safeguards the continuation of the civilized society. However,"Li" is an aesthetic education, and it is the entire social community as the final destination."Li" can play a corresponding social function and political role. The purpose of "Li" is to promote respect and humility, benevolent tolerance, civilized harmony, and coincide with the requirements of socialist core values. "Li"is the most important part of the aesthetic education thought. This can enable the people to organize and unite in an orderly manner, smoothly carry out production and life, and maintain social production activities."Li" is actually the glue of interpersonal social relations, enhances the cohesion of the nation, dissolves the country's division, and integrates the spiritual power of unification. In the course of human history, before human beings move towards true equality, they must experience a long hierarchy society. This is an objective necessity for historical development. Before people embrace real equality, they must first 
emerge from barbarism to demonstrate civilization, gain morality, and shape ideal personality.. These are the unique ritual functions of Chinese traditional culture. It is this ritual function that is unique in the world that can make China a well-deserved state of ceremonies, making China a great country and making China's culture more than 5,000 years old.

The aesthetics of aesthetic education in aesthetic education does not mean simple entertainment, but a way that humans use when they know the truth and cultivate moral character. Aesthetics are subordinate to education, and true aesthetic education must be clearly defined by the purpose of education. Therefore, regardless of the characteristics of education and educational effectiveness of the United States and the United States is the formalism of education, so aesthetic education in addition to artistic education means, the choice of education in the education so that students enjoy aesthetic education is one of them. Teachers can make the teacher-student relationship harmonious, so that students can learn easily and happily, and they can think positively. Only in this way can they be called inspirational enlightenment.

\section{References}

[1] Zhu Guofang. Research on the aesthetic cultural meaning of "Book of Rites" [D]. Jinan: Shandong University, 2013.

[2] Wang Qifa. The Personality Ideal and Social Ideal in The Book of Rites[J]. Journal of the Graduate School of the Chinese Academy of Social Sciences, 1990.04.

[3] Wang Wenjin. Translation of "Book of Rites" [M]. Beijing: Zhonghua Book Company, 2001.

[4] Sun Rongchun. An Analysis of the Aesthetic Education Thought in The Book of Rites[J]. Journal of Xuzhou Normal University (Social Science Edition), 2009.06.

[5] Sheng Banghe. "Book of Rites" and Chinese Rite Culture [J]. Jiangsu Social Sciences, 2009.01.

[6] Zeng Fanren. On the Modern Significance of Aesthetic Education [J]. Journal of Shandong University (Social Philosophy), 1999.07.

[7] Fehl Noah Edward .Rites and Propriety in Literature and Life-A perspective for a cultural history of ancient China[M].Chinese University of Hong Kong Press, 1971.

[8] Zujie Yuan.Dressing for power: Rite, costume, and state authority in Ming Dynasty China[J]. Frontiers of History in China2007, 2(2): 181-212.

[9] Wu Xiaoqun.The Rites of Mourning in Archaic and Classical Greece and in Pre-Qin China[J]. Fudan Journal of the Humanities and Social Sciences2014, 2(8): 235-270. 